\title{
Pain assessment using the Adolescent Pediatric Pain Tool: A systematic review
}

\author{
Ananda Maria Fernandes PhD¹, Catarina De Campos BSN 1 , Luis Batalha PhD ${ }^{1}$, Ana Perdigão MSc ${ }^{1}$, Eufemia Jacob PhD ${ }^{2}$
}

\begin{abstract}
A Fernandes, C De Campos, L Batalha, A Perdigão, E Jacob. Pain assessment using the Adolescent Pediatric Pain Tool: A systematic review. Pain Res Manag 2014;19(4):212-218.

BACKGROUND: The Adolescent Pediatric Pain Tool (APPT) is a multidimensional pain assessment tool designed to assess pain location (body outline diagram), intensity (word graphic rating scale) and quality (list of pain descriptors) in hospitalized children eight to 17 years of age.

OBJECTIVES: To identify the age range, health conditions, settings and purpose for which APPT has been used; the components of the APPT that have been used; and the reported clinical and research utility of the APPT. METHODS: A systematic review of published studies using the APPT was performed. Studies were identified through electronic searches in CINAHL, Medline, PubMed, SciELO and PsycInfo.

RESULTS: Twenty-three studies were analyzed. APPT has been used in patients between two and 68 years of age, with various acute and chronic conditions, in and out of hospital. All but six studies used the three components of the APPT. Most of the studies used the total number of sites marked, mean pain intensity and mean number of pain descriptors selected as main outcome measures; however, scoring methods varied. Studies report that the use of the APPT is relevant for clinical practice and for research.

CONCLUSION: Obtaining self-report of pain using the APPT may help clinicians to tailor pain management interventions. It may also be used in studies to provide a deeper understanding of the pain experience and to examine the effectiveness of pain management interventions. However, outcome measures and methods of scoring the different components of the APPT need to be clearly identified.
\end{abstract}

Key Words: Adolescent; Child; Pain; Pain measurement; Review

$\mathrm{P}^{\mathrm{a}}$ ain is very common among pediatric populations (1) and is one of the most common factors that impair quality of life $(2,3)$. Children and adolescents with pain may have their daily life activities seriously compromised, with up to $50 \%$ experiencing problems such as sleep, eating disorders, inability to pursue hobbies and decreased school attendance $(4,5)$.

Clinical decisions to treat pain, as well as clinical trials of pain interventions, rely on accurate assessment of pain. Pain perception is the result of a complex neural network that includes interrelated areas of the brain such as the somatosensory cortex, limbic and thalamocortical components that subserve the sensory-discriminative, affective-motivational and evaluative-cognitive dimensions $(6,7)$. Given the multidimensional nature of pain, a comprehensive assessment should include not only the intensity, but also the location and the quality of pain as outcome measures in clinical trials, as recommended by the Pediatric Initiative on Methods, Measurement, and Pain Assessment in Clinical Trials (PedIMMPACT) (8).

The selection of a multidimensional tool for pain assessment is not an easy task. The evaluator should choose tools that are valid and reliable, as well as tools that are informative about children/adolescent's pain experiences. In adults, the McGill Pain Questionnaire (MPQ) covers these dimensions and has been extensively used (9). Modelled after the MPQ, a multimensional tool for pain assessment was

\section{L'évaluation de la douleur à l'aide de l'outil d'évaluation pédiatrique de la douleur à l'adolescence : une analyse systématique}

HISTORIQUE : L'outil APPT d'évaluation pédiatrique de la douleur à l'adolescence est un outil multidimensionnel conçu pour évaluer le foyer (schéma du corps humain), l'intensité (échelle d'évaluation graphique en mots) et la qualité (liste de descripteurs de la douleur) de la douleur chez les enfants hospitalisés de huit à 17 ans.

OBJECTIFS : Déterminer les tranches d'âge, les maladies, les milieux et les raisons pour lesquels l'outil APPT a été utilisé, les volets de l'outil APPT qui ont été utilisés et l'utilité de l'outil APPT en clinique et en recherche.

MÉTHODOLOGIE : Les chercheurs ont mené une analyse systématique des études publiées faisant appel à l'outil APPT. Ils ont colligé les études au moyen de recherches électroniques dans CINAHL, Medline, PubMed, SciELO et PsycInfo.

RÉSULTATS : Les chercheurs ont analysé 23 études. L'outil APPT a été utilisé chez des patients de deux à 68 ans ayant diverses maladies aiguës et chroniques, en milieu hospitalier ou ambulatoire. Toutes les études, sauf six, faisaient appel aux trois volets de l'outil APPT. La plupart recouraient à tous les foyers indiqués, à l'intensité moyenne de la douleur et au nombre moyen de descripteurs de la douleur sélectionnés comme principales mesures des résultats cliniques, mais les modes de cotation variaient. D'après les études, l'utilisation de l'outil APPT est pertinente en pratique clinique et en recherche.

CONCLUSION : L'auto-évaluation de la douleur à l'aide de l'outil APPT peut aider les médecins à adapter les interventions de gestion de la douleur. Elle peut aussi être utilisée dans des études pour mieux comprendre l'expérience de la douleur et examiner l'efficacité des interventions de gestion de la douleur. Cependant, il faudrait déterminer clairement les mesures des résultats cliniques et les modes de cotation des divers volets de l'outil APPT.

developed to measure the intensity (9), location (10) and quality (11) of pain, known as the Adolescent Pediatric Pain Tool (APPT) $(11,12)$ for use in children and adolescents between eight and 17 years of age.

The APPT is composed of three independent parts: a body outline diagram (BOD) with a front and back view of body for children to mark the location of their pain; a word graphic rating scale (WGRS), which is a $10 \mathrm{~cm}$ line anchored by 'no pain', 'little pain', 'medium pain' and 'worst possible pain' to measure pain intensity; and a list of 67 pain quality descriptors to assess four dimensions of pain (sensory [eg, 'aching', 'burning']; affective [eg, 'awful', 'sickening']; evaluative [eg, 'annoying', 'terrible']; and temporal [eg, 'constant', 'sometimes']). Validity and reliability of the BOD for children eight to 17 years of age was established in 175 hospitalized children who marked the location of their pain on the BOD, and also indicated the pain in their body by pointing to where it was hurting, with an observer marking the BOD. Evidence of convergent validity was supported by high correlations $(\mathrm{r}=0.83)$ between the marking on the BOD and the areas marked by the observer on the BOD (10). Validity and reliability of the WGRS was established using five pain-intensity scales that were presented to healthy and hospitalized children. Among the five scales, the WGRS was preferred by hospitalized children and, therefore, was selected as part of the APPT for measurement of pain intensity. Convergent validity and feasibility were assessed in 35 children who used the five 
different pain intensity scales. Convergent validity was supported with high correlations ( $r=0.68$ to $r=0.97)$ among the five scales. Test-retest reliability was supported with high correlations $(r=0.91)$ of pain ratings on case scenarios with different levels of pain intensity, measured on two separate occasions (9). High sensitivity was indicated when 55 children reported a decrease in pain intensity from day 2 to day 5 of the postoperative period.

The list of pain descriptors that were included in the APPT was developed in three phases involving 1223 children eight to 17 years of age, including both healthy and hospitalized children (11). In phase 1, both healthy children and children with cancer sorted 129 pain descriptors retrieved from the literature as words they knew, words they use to describe pain and words they did not know. Among these, 56 were indicated as words they would use to describe pain. In phase 2, hospitalized children used the APPT to describe their pain. A moderate correlation was found between the number of pain descriptors, and both pain intensity and the number of sites marked on a BOD. Evaluative pain descriptors were more related to pain intensity $(\mathrm{r}=0.44 ; \mathrm{P}<0.01)$ than sensory $(\mathrm{r}=0.35 ; \mathrm{P}<0.01)$ or affective dimensions $(r=0.38 ; \mathrm{P}<0.01)$. The number of descriptors of the sensory, affective and evaluative dimensions were highly correlated. In phase 3, the validity and reliability of the pain descriptors were tested. The number of total, sensory and affective descriptors significantly decreased $(\mathrm{P}<0.001, \mathrm{P}<0.001$ and $\mathrm{P}<0.05$, respectively) from postoperative day 1 to day 3 , indicating construct validity. The number of descriptors of each dimension were highly correlated between measurements at two time points $(\mathrm{r}=0.95 ; \mathrm{P}>0.001)$. Eleven temporal descriptors were added and validated in a subsequent study (12).

Although the validity and reliability of the APPT is well established in hospitalized children and adolescents eight to 17 years of age, there is little information regarding the use of the APPT in other age groups and settings. The specific aims of the present review were to identify the age ranges, clinical conditions and settings in which the APPT has been used; to determine which components of the APPT have been used; and to identify reported strengths and limitations of its use in clinical practice and research.

\section{METHODS}

A systematic review of the literature was conducted following the methods outlined by the Joanna Briggs Institute (13) as described in this section.

\section{Search strategy}

The search was conducted in three phases. In phase 1, an initial search was conducted in PubMed, CINAHL and Medline using the term "Adolescent Pediatric Pain Tool" to retrieve articles that used the APPT, to examine the key words used and identify additional relevant terms for our search.

No systematic reviews were found. In phase 2, the literature search was performed in CINAHL, Medline, PubMed, SciELO and PsycINFO (1990 to the third week of May 2011), using the terms "Adolescent Pediatric Pain Tool" OR APPT, pain, child OR adolescent in the title and abstract, with no other limitations. The literature search was also performed in Portuguese using the same translated terms. In phase 3, a manual search of reference lists from relevant articles was performed to identify other relevant studies.

\section{Criteria for considering studies for the present review}

Inclusion criteria were defined in terms of population, settings, outcome measures and type of study. All age groups and health conditions were included. Both hospital/clinic and community/home settings were considered to integrate the present review. Pain measurement had to include the APPT or its components, with or without other measures of pain. The review considered all primary quantitative and qualitative studies published in English and Portuguese. Unpublished data, reviews, guidelines, commentaries and abstracts were not eligible for inclusion.

\section{Methods of review}

One reviewer (CC) performed the literature search and examined all titles for relevance. All relevant titles were retained and abstract reading was performed. Two reviewers (CC, AF) independently assessed the full texts and evaluated eligibility for inclusion. All studies were also assessed for methodological quality using criteria described in the next section. Disagreements were discussed until consensus was reached.

Data were extracted to obtain a descriptive summary of the use of the APPT in each study. Extraction covered sample characteristics (size, age and health condition), setting, purpose, study design, outcome measures, and clinical and research utility. Clinical utility pertains to the usefulness of the tool for health-related decision making regarding pain control as well its feasibility in clinical practice. Research utility concerns the validity and reliability of the tool.

\section{Critical appraisal of included studies}

Although the quality of the studies was not an inclusion criterion, this appraisal was considered to be useful to interpret the results.

The quality of experimental studies was assessed using the Meta Analysis of Statistics Assessment and Review Instrument (MAStARI) for randomized controlled/pseudorandomized trials, which examined randomization, allocation, outcome measures and statistical analyses. The quality of observational studies was assessed using the MAStARI for comparable cohort/case control studies or the MAStARI for descriptive/case series studies. Both methodologies examined the representativeness and homogeneity of the samples, confounding factors, reliability and validity of outcome measures, and appropriateness of statistical analyses. The qualitative study was assessed using the Quality Assessment and Review Instrument critical appraisal tool, which examined the congruity among the philosophical perspective, methodology, analyses and representation of the results (13).

The items were rated as: 'Yes' (the study met criteria for the item); 'No' (the study did not meet the criteria for the item); 'Unclear' (it is not clear that the study met the criteria); and 'Not applicable'.

\section{Search outcome}

\section{RESULTS}

Between January 1990 and May 2011, 330 references were found using the search terms. They were primarily retrieved from CINAHL and Medline. No results were found in SciELO and PsycINFO. From the 330 references, only 94 titles were considered relevant. However, 74 references were excluded because they did not assess pain $(n=28)$, did not use APPT for pain measurement $(n=32)$, were reviews $(n=6)$ and guidelines $(n=3)$, or were not available electronically or in local library services $(n=5)$. Therefore, 20 studies were retained for full-text reading and subsequently included. Two additional studies $(14,15)$ were found from manual searches of reference lists and added to the body of studies. An update of the search was made in March 2014 using the same search strategy and two publications were retrieved: one was excluded for being a review and the other was included (16). Thus, the final review consisted of 23 studies (Figure 1).

\section{Methodological quality appraisal}

The appraisal of the methodological quality revealed that most of the studies identified the inclusion criteria and used recruitment methods that minimized risk of bias. Statistical analysis was appropriate in all quantitative studies. The limitations most frequently encountered were related to nonrandomization of sample, confounding factors not clearly defined and no evidence of the reliability of outcome measurement.

\section{Aims and methods of included studies}

Studies were categorized into three groups: studies that examined the pain experience of children and its correlates (15-28); studies that assessed pain management - namely, the effects of hydromorphone patient-controlled analgesia (14), intravenous analgesics $(29,30)$, 


\begin{tabular}{|c|}
\hline 330 references identified (2011 search) \\
\hline$\downarrow$ \\
\hline $\begin{array}{l}236 \text { references excluded by title reading (including } \\
\text { repetitions) }\end{array}$ \\
\hline$\downarrow$ \\
\hline 94 references included for abstract reading \\
\hline$\downarrow$ \\
\hline $\begin{array}{c}74 \text { references excluded by abstract reading } \\
28 \text { did not assess pain } \\
32 \text { did not use APPT } \\
6 \text { reviews } \\
3 \text { guidelines } \\
5 \text { unable to acess full text } \\
\end{array}$ \\
\hline$\downarrow$ \\
\hline $\begin{array}{l}20 \text { references included for full text reading plus } \\
2 \text { references found from manual search }\end{array}$ \\
\hline$\downarrow$ \\
\hline 2 references identified (2014 search) \\
\hline$\downarrow$ \\
\hline $\begin{array}{c}1 \text { reference excluded by abstract reading } \\
1 \text { review }\end{array}$ \\
\hline$\downarrow$ \\
\hline 23 references included in the review \\
\hline
\end{tabular}

Figure 1) Flow chart of the search outcome. APPT Adolescent Pediatric Pain Tool

distraction (31) and analgesic prescriptions - in surgical in-patients and day patients; and feasibility studies (32-34).

Most of the studies $(n=20)$ were quantitative, one being experimental (31) and the others descriptive. One study was qualitative, using grounded theory (18), and another was a mixed-method study (22). One reference was a case report and was included for examination of clinical utility of the APPT (19).

Data were collected by self-report using paper and pencil in 22 studies. In two of these that included young children, children were assisted by the parents, caregivers or researchers $(16,15)$. In one study involving preschool-age children (20) the APPT was completed by the parents. One study collected the data by telephone on day 3 after surgical procedure (35).

\section{Participants' age, health condition and setting}

The APPT has been used in 1750 participants ranging from two to 68 years of age. Twelve studies included only participants between eight and 17 years of age, the range for which the tool was originally validated. Health conditions included sickle cell disease in six studies, surgical procedures in five, cancer in four, blunt trauma injury in two, venipuncture in two, Morquio A syndrome in one, HIV in one, allergy testing in one and various medical problems (infections, cardiac, etc) in one. Although the APPT was used predominantly in hospitalized patients, it was also used in outpatient clinics $(17,23,33)$, in community facilities (25) and at home $(21,32,36)$. Table 1 presents the studies and information on sample size, age, health conditions, settings and components of the APPT used.
Components of the APPT used

To determine the utility of the scale, the components and outcome measures used were examined. Nearly one-quarter of the studies (74\%) used the three components of the APPT. Four studies $(24,30,32,35)$ used the WGRS, and two studies $(15,17)$ used the BOD and the list of pain descriptors. Within the components used, studies varied regarding the outcome measures.

Table 2 presents the number of studies that used each component of the APPT and the corresponding outcome measures.

\section{Report on the clinical utility of the APPT}

Studies indicated the benefits of using the APPT for clinical practice. Overall, APPT was considered to be helpful to make decisions about pain management (Table 3). Two studies $(19,27)$ suggested that APPT should be incorporated into routine pain assessment of children.

A major advantage of the APPT reported was its ability to indicate pain location and quality. The BOD was important not only for identifying sites of pain in the body (25), but also for quantifying the extensiveness or spatial distribution of pain in the body $(15,25)$. Furthermore, extensiveness of the pain indicated in the BOD was useful in the evaluation of drug effects after administration (14). Also, pain location was found to be useful in predicting the amount of analgesia a patient would need (29). The use of pain descriptors was clinically useful to gain a more comprehensive assessment of the different pain dimensions (affective, cognitive, evaluative and temporal). In addition, the pain descriptors may be used as outcomes for evaluating the effectiveness of pain management interventions (14). For example, words such as 'uncontrollable' and 'never goes away' indicate ineffectiveness in pain management (15). One study indicated the lack of clinically significant decrease in pain intensity (15), and recommended that dimensions such as pain location and pain quality were more informative for assessing effectiveness of pain management strategies.

Feasibility is also an important feature. The APPT was described as readily understood and completed (36). Only Crandall et al (22) reported on limitations of the APPT for clinical use. The major limitation was that clinicians did not know about the APPT or found it was not readily available. Also, clinicians believed it was time consuming (19), although Savedra et al (34) report that the mean time to complete the APPT varied between $3.2 \mathrm{~min}$ and $6.4 \mathrm{~min}$.

Four studies $(17,27,34,36)$ documented patients' ability to use the APPT without difficulty, and one study also reported on willingness to use the APPT (34).

\section{Report on the research utility of the APPT}

The psychometric properties of the APPT reported in studies involving children eight to 17 years of age have been summarized in a recent review (37). APPT was also used in children $<8$ years of age (20), and adults $>17$ years of age $(20,25,29,36)$; however, reliability and validity data were not reported. Granados and Jacob (29) reported that the young adult patients with sickle cell disease in their study used the APPT during adolescence and that it was previously used in adults with sickle cell disease in another report (23). In both reports, no information on reliability and validity in their sample was provided. Holzemer et al (25) stated that the APPT was found to be appropriate and acceptable for adults with AIDS after a small pilot study; however, no data were provided related to reliability and validity in the pilot study.

Two studies reported on convergent validity among the WGRS and the African-American Oucher (30) and the numerical rating scale (17), both with high correlations. One study reported the development and content validation in a small number of Spanishspeaking children (32). The Spanish version was reduced to 66 words because one descriptor was similar to another translated word. Testretest reliability was performed with three children and acceptable scores were obtained. Another study (17) reported a reliability analysis of the three components of the Spanish APPT and showed that the total number of body locations marked, the pain intensity rating 
TABLE 1

Age of participants, setting and components of the Adolescent Pediatric Pain Tool (APPT), according to health condition

\begin{tabular}{|c|c|c|c|c|}
\hline First author (reference), year & $\mathrm{n}$ & Age, years & Setting & Components of the APPT used \\
\hline \multicolumn{5}{|l|}{ Sickle cell disease } \\
\hline Crandall (19), 2005 & 1 & 11 & Hospital & BOD, WGRS, list of pain descriptors \\
\hline Granados (29), 2009 & 19 & $20-56$ & Hospital & BOD, WGRS, list of pain descriptors \\
\hline Jacob (15), 2003 & 27 & $5-19$ & Hospital & $\mathrm{BOD}$, list of pain descriptors \\
\hline Jacob (14), 2008 & 5 & $>8$, mean 16.2 & Hospital & BOD, WGRS, list of pain descriptors \\
\hline Gillies (36), 1997 & 6 & $12-20$ & Hospital & BOD, WGRS, list of pain descriptors \\
\hline Gillies (35), 2001 & 351 & $12-18$ & Hospital, home & WGRS \\
\hline Kotzer (24), 2000 & 93 & $8-21$ & Hospital & WGRS \\
\hline Savedra (34), 1993 & 65 & $8-17$ & Hospital & BOD, WGRS, list of pain descriptors \\
\hline Young (28), 1994 & 23 & $11-20$ & Hospital & BOD, WGRS, list of pain descriptors \\
\hline \multicolumn{5}{|l|}{ Cancer } \\
\hline \multicolumn{5}{|l|}{ Venipuncture } \\
\hline Bournaki (26), 1997 & 94 & $8-12$ & Hospital & BOD, WGRS, list of pain descriptors \\
\hline van Cleve (27), 1996 & 90 & $7-12$ & Hospital & BOD, WGRS, list of pain descriptors \\
\hline \multicolumn{5}{|l|}{ Blunt trauma injury } \\
\hline Crandall (22), 2002 & 13 & $11-17$ & Hospital & BOD, WGRS, list of pain descriptors \\
\hline Crandall (18), 2007 & 13 & $11-17$ & Hospital & BOD, WGRS, list of pain descriptors \\
\hline \multicolumn{5}{|l|}{ HIV positive } \\
\hline Holzemer (25), 1998 & 249 & $23-68$ & Hospital, home, community & BOD, WGRS, list of pain descriptors \\
\hline \multicolumn{5}{|l|}{ Morquio A syndrome } \\
\hline Hendriksz (16), 2014 & 36 & $7-12$ & Community & BOD, WGRS, list of pain descriptors \\
\hline
\end{tabular}

BOD Body outline diagram; WGRS Word graphic rating scale

TABLE 2

Components of the Adolescent Pediatric Pain Tool, outcome variables and number of studies

\begin{tabular}{|c|c|c|c|}
\hline Component & Studies, $\mathbf{n}$ & Outcome variables & Studies, $n$ \\
\hline \multirow[t]{3}{*}{ Body outline diagram } & 19 & Total number of sites & 13 \\
\hline & & Location of most frequently marked site & 4 \\
\hline & & Surface area & 2 \\
\hline \multirow{5}{*}{$\begin{array}{l}\text { Word graphic rating } \\
\text { scale }\end{array}$} & 21 & Mean pain intensity & 12 \\
\hline & & Pain in 3 categories: low, high, worst pain & 1 \\
\hline & & Pain in 4 categories: no pain $(0)$, mild $(1-3)$, moderate $(4-6)$ and severe $(7-10)$ & 1 \\
\hline & & Pain in 5 categories: 0 (no pain) to 4 (most pain ever) & 2 \\
\hline & & Not reported & 5 \\
\hline \multirow[t]{6}{*}{ Pain quality descriptors } & 19 & Mean number of words selected & 13 \\
\hline & & Mean number of words selected in sensory, affective, evaluative, temporal dimensions & 8 \\
\hline & & Percentage of words selected & 1 \\
\hline & & Percentage of words selected in sensory, affective, evaluative, temporal dimensions & 2 \\
\hline & & Number of participants reporting $\geq 1$ word in sensory, affective, evaluative, temporal dimensions & 1 \\
\hline & & Not reported & 1 \\
\hline
\end{tabular}

on the WGRS and the total number of words selected exhibited high internal consistency (Cronbach's alpha $=0.729$ ). One study reported the use of the APPT descriptors in Chinese (20); however, no information was provided on the psychometric properties of the Chinese version.
Sensitivity to changes in pain status was documented in one study by indicating that pain intensity decreased after pain management (21). Sensitivity of the number of pain sites marked on the BOD and the number of quality pain descriptors were documented in another study, indicating a decrease in these numbers after opioid administration (14). 
TABLE 3

Clinical utility of the Adolescent Pediatric Pain Tool reported in published studies

\begin{tabular}{ll}
\hline First author (reference), year & Clinical utility \\
\hline $\begin{array}{l}\text { Crandall (18), 2007; Crandall (19), 2005; } \\
\text { Crandall (22), 2002; Savedra (34), 1993 }\end{array}$ & Provides information on etiology, influencing factors, impact on daily life, patterns and quality of pain \\
$\begin{array}{l}\text { Crandall (19), 2005; Jacob (15), 2003; } \\
\text { Savedra (34), 1993 }\end{array}$ & Provides information on progress of pain during the course of hospitalization \\
$\begin{array}{l}\text { Crandall (22), 2002; van Cleve (21), 2004; } \\
\text { Jacob (15), 2003; Franck (23), 2002 }\end{array}$ & Provides information on efficacy of pain management interventions \\
$\begin{array}{l}\text { Crandall (19), 2005 } \\
\text { Crandall (19), 2005 }\end{array}$ & Helps clinicians to design interventional plans tailored to physical and psychosocial patients' functions \\
$\begin{array}{l}\text { Granados (29), 2009 } \\
\text { Crandall (18), 2007; Crandall (22), 2002; }\end{array}$ & $\begin{array}{l}\text { Pain location information can be useful in predicting the amount of analgesia a patient will need } \\
\text { Franck (23), 2002; van Cleve (27), 1996 to talk about their own pain experiences in a concrete way }\end{array}$
\end{tabular}

TABLE 4

Research utility of the Adolescent Pediatric Pain Tool reported in published studies

\begin{tabular}{|c|c|}
\hline First author (reference), year & Research utility \\
\hline Jacob (17), 2008; Gillies (36), 1997; van Cleve (27), 1996; Savedra (34), 1993 & Appropriate to ages $8-17$ years \\
\hline $\begin{array}{l}\text { Crandall (18), 2007; Crandall (22), 2002; Franck (23), 2002; van Cleve (27), } \\
1996\end{array}$ & Stimulates patients to talk about their own pain experiences in a systematic way \\
\hline Gillies (36), 1997 & Data are easy to score and analyze \\
\hline Jacob (17), 2008; van Cleve (21), 2004 & Construct validity is established \\
\hline Jacob (14), 2008 & High internal consistency \\
\hline Jacob (15), 2003 & Body outline diagram is helpful to quantify the extent of pain \\
\hline Beyer (30), 2000; Jacob (14), 2008 & $\begin{array}{l}\text { Convergent validity of the word graphic rating scale with the African-American } \\
\text { Oucher and the numerical rating scale is established }\end{array}$ \\
\hline Crandall (19), 2005 & List of pain descriptors captures the essence of pain experience \\
\hline Franck (20), 2004; van Cleve (33), 2001 & Available in Spanish and Chinese \\
\hline
\end{tabular}

Regarding feasibility, one study reported that the APPT was easy to score and analyze (36). Reports on research utility are summarized in Table 4.

\section{DISCUSSION}

A systematic review of international research involving the APPT is presented. The search strategy found a total of 23 primary research studies that addressed the APPT. The inclusion of English and non-English versions may be considered to be a strength of the present review. All of the studies included addressed relevant issues regarding the assessment of pain.

The APPT was originally validated for hospitalized children eight to 17 years of age who speak English. However, it has been used in a wide range of ages, health conditions and settings. It was extended to both younger and older age groups, which may indicate the need for a multidimensional tool for these groups. However, while the psychometric properties have been well described in children eight to 17 years of age, no information on the psychometric properties for other age groups was available. It is necessary to ascertain whether children know and understand the meaning of the words used as pain descriptors for use of the tool in children $<8$ years of age.

A variety of health conditions have been studied using the APPT, supporting the use of the tool in acute conditions (eg, postoperative, blunt traumatic injury, various medical conditions) including procedural pain (eg, venipuncture, allergy testing). The APPT was also used in chronic conditions (eg, cancer and sickle cell disease) during acute hospitalizations. However, it is unclear from these studies whether these patients with chronic conditions had acute or persistent pain. Future studies are needed to determine whether the APPT is useful in patients with chronic and persistent pain.

Regarding the settings, it was used not only in hospitalized patients but also proved to be useful in outpatient clinics, in community facilities and at home.
Versions of the APPT have been developed in other languages. Our data, as well as a recently published analysis of the psychometric properties of the tool (37), support the use of the English and Spanish versions; however, the development of the Chinese version needs to be described and its psychometric properties studied.

The three components of the APPT were used together in the majority of studies. The most frequently used component of the APPT was the WGRS, followed by the list of pain descriptors; fewer studies used the BOD.

The assessment of pain location indicated not only the most common sites marked, but also the number of sites marked and the extensiveness of the pain by quantifying the surface area on the $\mathrm{BOD}$, making the BOD quantifiable. However, different scoring methods have been used, which makes it difficult to compare across studies. Although the original scoring instructions mention the areas most commonly marked and the number of sites marked on the BOD as outcomes, there is little information about the scoring methods for determining surface areas. The clinical usefulness and interpretability of obtaining the surface area in pain remains to be confirmed. Future studies are needed to determine the best methods for scoring the $\mathrm{BOD}$ that would be meaningful for both research and clinical practice.

Children did not have difficulty indicating pain intensity on the WGRS. However, if clinicians are not trained about the scoring of the WGRS, it will not be clinically useful because it may require the use of another measure of intensity to obtain the same degree of precision. Therefore, futher studies are needed to determine innovative ways of automatically scoring the WGRS and other components of the APPT to minimize clinicians' burden.

Similarly, pain descriptors were also assessed in different ways, such as the total number of words selected and number of words selected in each dimension. Unlike the MPQ, the pain descriptors are not given 
an intensity score and it has not been established that fewer pain descriptors represent less pain. Consequently, the usefulness of these outcomes is questionable until an external criterion can be found. Also, it would be interesting in future studies to determine whether different pain conditions have different pain descriptor profiles - ie, whether the use of some descriptors may be clinically useful to diagnose neuropathic pain.

There is sufficient evidence to support the use of the APPT to explore the pain experience of patients and examine its correlates because the reports describe these experiences in a comprehensive, multidimensional manner. More studies are needed to recommend the use of the APPT to study the effectiveness of interventions because it was used in only one experimental study (31). Studies examining patterns of analgesia revealed a decrease not only in pain intensity, but also in the number of painful areas and pain descriptors. However, the relationship among these three outcomes remains to be determined. The outcome variables and methods of scoring the different components of the APPT need to be clearly identified, and consistently used in research protocols to allow comparisons of data from different studies. Future studies are needed to determine whether all pain outcome variables measured in the APPT are relevant to identify clinically significant changes in trials of pain management interventions. Furthermore, development of a composite pain index would allow one single score to reflect the different dimensions of the pain experience.

Limitations of the current review include the unavailability of some articles for full-text reading, despite our efforts to obtain them. Also, our search strategy might have produced more results using the terms in all fields rather than in the title and abstract only. The decision to include all studies, irrespective of their methodological

\section{REFERENCES}

1. Huguet A, Miró J. The severity of chronic pediatric pain: An epidemiological study. J Pain 2008;9:226-36.

2. Gold J, Yetwin A, Mahrer N, et al. Pediatric chronic pain and health-related quality of life. J Pediatr Nurs 2009;24:141-50.

3. Enskär K, Essen L. Physical problems and psychosocial function in children with cancer. Paediatr Nurs 2008;20:37-41.

4. Roth-Isigkeit A, Thyen U, Stöven H, Schwarzenberger J, Schmucker P. Pain among children and adolescents: Restrictions in daily living and triggering factors. Pediatrics 2005;115:e152-62.

5. Konijnenberg AY, Uiterwaal CS, Kimpen JL, van der Hoeven J, Buitelaar JK, de Graeff-Meeder ER. Children with unexplained chronic pain: Substantial impairment in everyday life. Arch Dis Child 2005;90:680-6.

6. Melzack R. From the gate to neuromatrix. Pain 1999;6:S212-26.

7. Melzack R. The McGill Pain Questionnaire. Anesthesiology 2005;103:199-202.

8. McGrath P, Walco G, Turk D, et al. Core outcome domains and measures for pediatric acute and chronic/recurrent pain clinical trials: PedIMMPACT recommendations. J Pain 2008;9:771-83.

9. Tesler M, Savedra M, Holzemer W, Wilkie D, Ward J, Paul S. The word-graphic rating scale as a measure of children's and adolescents' pain intensity. Res Nurs Health 1991;14:361-71.

10. Savedra M, Tesler M, Holzemer W, Wilkie D, Ward J. Pain location: Validity and reliability of body outline markings by hospitalized children and adolescents. Res Nurs Health 1989;12:307-14.

11. Wilkie D, Holzemer W, Tesler M, Ward J, Paul S, Savedra M. Measuring pain quality: Validity and reliability of children's and adolescents' pain language. Pain 1990;41:151-9.

12. Savedra M, Tesler M, Holzemer W, Brokaw P. A strategy to assess the temporal dimension of pain in children and adolescents. Nurs Res 1995;44:272-6.

13. The Joanna Briggs Institute. Reviewers' Manual: 2011 edition. The Joanna Briggs Institute, 2011:200.

14. Jacob E, Hockenberry M, Mueller B. Effects of patient controlled analgesia hydromorphone during acute painful episodes in adolescents with sickle cell disease: A pilot study. J Pain Manag 2008;1:173-8.

15. Jacob E, Miaskowski C, Savedra M, Beyer J, Treadwell M, Styles L. Changes in intensity, location, and quality of vaso-occlusive pain in children with sickle cell disease. Pain 2003;102:187-93. quality, enabled us to attain our aims but is also a limitation to the strengths of our results regarding clinical and research utility of the APPT. The fact that there was no evidence supporting the reliability of outcome measurements in some studies and that studies used different outcome measures highlights the need to standardize scoring methods.

\section{CONCLUSION}

The APPT has been widely used among pediatric populations with a variety of clinical conditions. Data support the use of the APPT for assessment of acute pain in hospitalized and nonhospitalized children and adolescents eight to 17 years of age; however, reliability in other age groups needs further examination. Use of versions in other languages should be supported by studies reporting the procedures followed to ensure semantic and cultural adaptation. Depending on the specific objectives of a study, different components of the APPT can be used as a primary outcome; however, scoring methods and a core of pain outcome measures should be considered to allow comparison between studies. The APPT is recommended for routine use in clinical practice and research when a more comprehensive understanding of pain experiences is needed.

INSTITUTIONS: Nursing School of Coimbra and University of California in Los Angeles School of Nursing.

FUNDING: The study was funded by the Fundação para a Ciência e Tecnologia (FCT) - PTDC/PSI-PCL/114652/2009. The funding agency played no role in the conduct of the research.

16. Hendriksz CJ, Lavery C, Coker M, et al. Burden of disease in patients with Morquio A syndrome: Results from an international patient-reported outcomes survey. Orphanet J Rare Dis 2014;9:32.

17. Jacob E, Mccarthy K, Hockenberry M. Quality of pain in Spanishspeaking children with cancer. Pediatr Nurs 2008;34:45-52.

18. Crandall M, Kools S, Miaskowski C, Savedra M. Adolescents' pain experiences following acute blunt traumatic injury: Struggle for internal control. J Spec Pediatr Nurs 2007;12:224-37.

19. Crandall M, Savedra M. Multidimensional assessment using the adolescent pediatric pain tool: A case report. J Spec Pediatr Nurs 2005;10:115-23.

20. Franck L, Kools S, Kennedy C, Kong S, Chen J, Wong T. The symptom experience of hospitalised Chinese children and adolescents and relationship to pre-hospital factors and behaviour problems. Int J Nurs Stud 2004;41:661-9.

21. Van Cleve L, Bossert E, Beecroft P, Adlard K, Alvarez O, Savedra M. The pain experience of children with leukemia during the first year after diagnosis. Nurs Res 2004;53:1-10.

22. Crandall M, Miaskowski C, Kools S, Savedra M. The pain experience of adolescents after acute blunt traumatic injury. Pain Manag Nurs 2002;3:110-4.

23. Franck L, Treadwell M, Jacob E, Vichinsky E. Assessment of sickle cell pain in children and young adults using the adolescent pediatric pain tool. J Pain Symptom Manag 2002;23:114-20.

24. Kotzer A. Factors predicting postoperative pain in children and adolescents following spine fusion. Issues Compr Pediatr Nurs 2000;23:83-102.

25. Holzemer W, Henry S, Reilly C. Assessing and managing pain in AIDS care: The patient perspective. J Assoc Nurses AIDS Care 1998;9:22-30.

26. Bournaki M. Correlates of pain-related responses to venipunctures in school-age children. Nurs Res 1997;46:147-54.

27. Van Cleve L, Johnson L, Pothier P. Pain responses of hospitalized infants and children to venipuncture and intravenous cannulation. J Pediatr Nurs 1996;11:161-8.

28. Young N, Bell D, Anthony A. Pediatric pain patterns during ilizarov treatment of limb length discrepancy and angular deformity. J Pediatr Orthop 1994;14:352-7.

29. Granados R, Jacob E. Pain experience in hospitalized adults with sickle cell disease. Medsurg Nurs 2009;18:161-82. 
30. Beyer J. Judging the effectiveness of analgesia for children and adolescents during vaso-occlusive events of sickle cell disease. J Pain Symptom Manag 2000;19:63-72.

31. Jeffs D. A pilot study of distraction for adolescents during allergy testing. J Spec Pediatr Nurs 2007;12:170-85.

32. Gedaly-Duff V, Lee K, Nail L, Nicholson H, Johnson K. Pain, sleep disturbance, and fatigue in children with leukemia and their parents: A pilot study. Oncol Nurs Forum 2006;33:641-6.

33. Van Cleve L, Muñoz C, Bossert E, Savedra M. Children's and adolescents' pain language in Spanish: Translation of a measure. Pain Manag Nurs 2001;2:110-8.

34. Savedra M, Holzemer W, Tesler M, Wilkie D. Assessment of postoperation pain in children and adolescents using the adolescent pediatric pain tool. Nurs Res 1993;42:5-8.
35. Gillies M, Smith L, Parry-Jones W. Postoperative pain: A comparison of adolescent inpatient and day patient experiences. Int J Nurs Stud 2001;38:329-37.

36. Gillies M, Parry-Jones W, Smith L. Post-operative pain in adolescents: A pilot study. J Clin Nurs 1997;6:77-8.

37. Jacob E, Mack AK, Savedra M, Van Cleve L, Wilkie DJ. Adolescent pediatric pain tool for multidimensional measurement of pain in children and adolescents. Pain Manag Nurs 2013 July 16 (Epub ahead of print). 


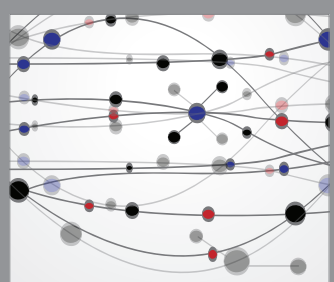

The Scientific World Journal
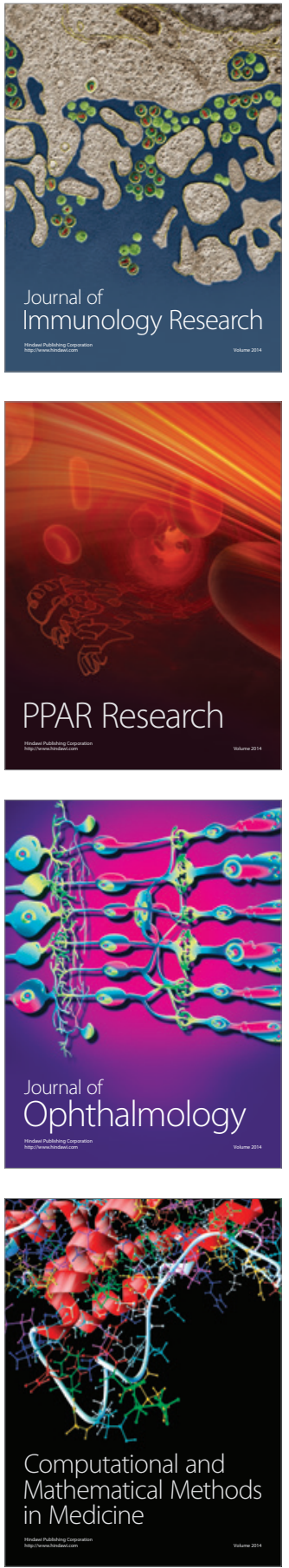

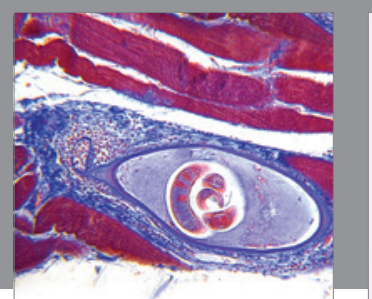

Gastroenterology Research and Practice

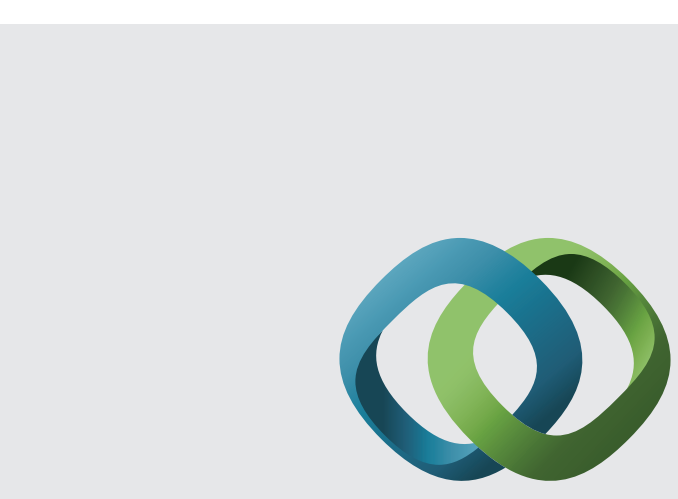

\section{Hindawi}

Submit your manuscripts at

http://www.hindawi.com

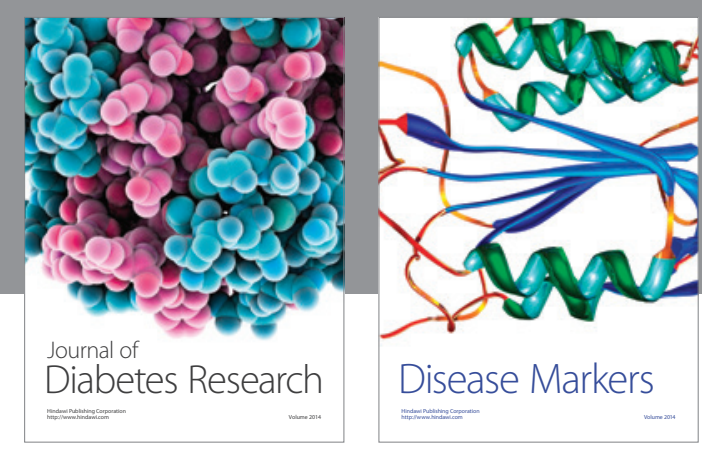

Disease Markers
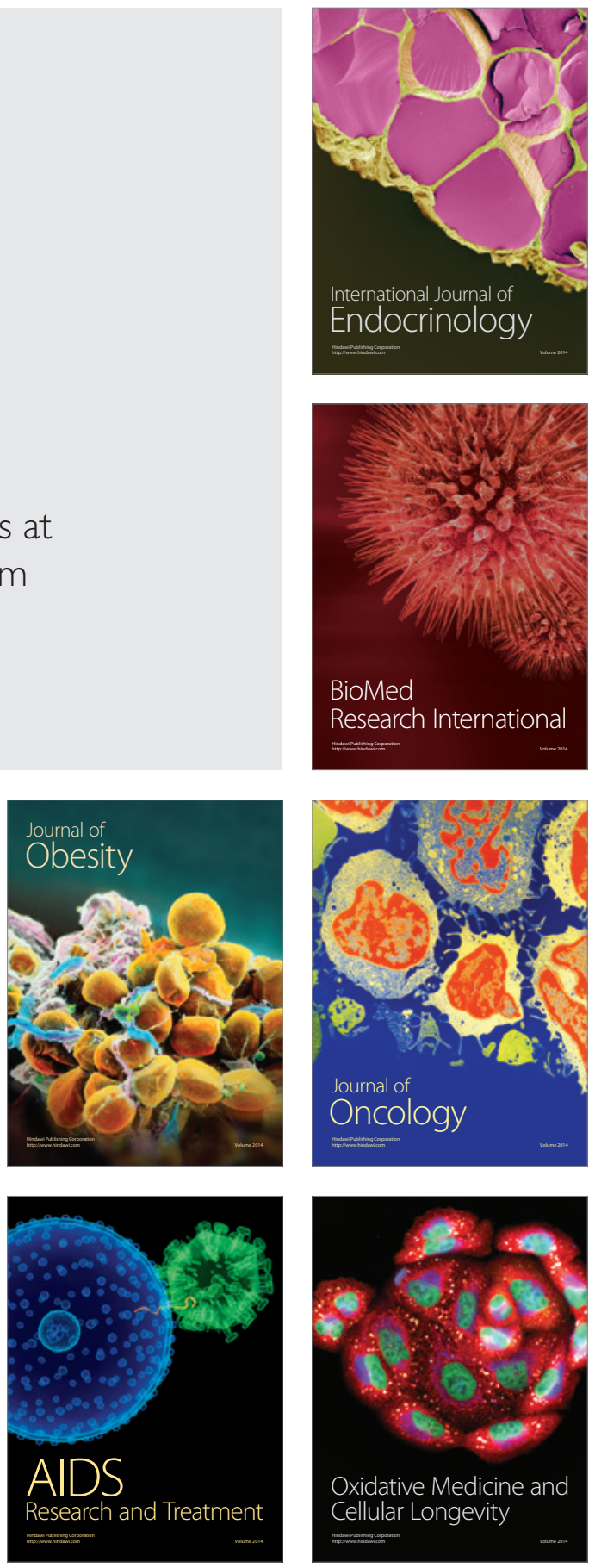